\title{
Cervantismo en el aula: funcionalización pedagógica del montaje escénico Dulcinea encadenada (compañía Teatro del Nuevo Mundo) en escuelas públicas de la región de Ñuble en Chile \\ Cervantism in the Classroom: \\ Pedagogical Functionalization of the Play Dulcinea encadenada (Teatro del Nuevo Mundo Company) in Public Schools of the Nuble Region in Chile
}

\section{Rodrigo Faúndez Carreño}

Universidad del Bío-Bío

rfaundez@ubiobio.cl

CHILE

\section{Francisca Medina Burgos}

Universidad del Bío-Bío

francisca.medina1501@alumnos.ubiobio.cl

CHILE

[Hipogrifo, (issn: 2328-1308), 9.1, 2021, pp. 1111-1122]

Recibido: 27-05-2020 / Aceptado: 25-06-2020

DOI: http://dx.doi.org/10.13035/H.2021.09.01.62

Resumen. Este artículo presenta la mediación pedagógica del montaje escénico Dulcinea encadenada de la compañía Teatro del Nuevo Mundo, aplicado en siete escuelas públicas de enseñanza básica y media de la Región de Ñuble en Chile. La intervención se sustentó en una metodología de investigación-acción por medio de un Taller de espectadores teatrales y un Cuadernillo didáctivo multimodal 
que articula contenidos tanto de la asignatura de Lengua y Literatura como los de Orientación. Ambos instrumentos didácticos avalan al teatro como una herramienta funcional a los contextos de educación formal.

Palabras clave. Cervantismo; didáctica; articulación pedagógica; teatro; Región de Ñuble, Chile.

Abstract. This article presents the pedagogical mediation of the play Dulcinea encadenada, by Teatro del Nuevo Mundo, applied in seven public primary and secondary schools in the Nuble Region in Chile. The intervention was an action research-based approach by means of a School for Theater Spectators and a Multimodal booklet, aligning contents of both 'Language and Literature' and 'School Counseling' subjects. Both didactic instruments endorse the theater as a functional tool when it comes to formal education.

Keywords. Cervantism; Didactic; Pedagogical alignment; Theater; Nuble Region, Chile.

«Si no realizamos la igualdad y la cultura dentro de la escuela, ¿dónde se podrán exigir estas cosas?»

(Gabriela Mistral, Magisterio y el niño, 1979)

\section{EL QUIJOTE DE LA MANCHA EN EL CURRÍCULUM ESCOLAR CHILENO}

La lectura y estudio de El ingenioso hidalgo don Quijote de la Mancha, de Miguel de Cervantes, se ha difundido en Chile a medida que se ha democratizado el acceso a la educación pública y mermado la brecha instructiva entre hombres y mujeres ${ }^{7}$. La primera edición chilena del Quijote es relativamente tardía, de 1863, una versión resumida impresa en Valparaíso por el librero español José Santos Tornero, bajo el título El ingenioso hidalgo don Quijote de la Mancha por Miguel de Cervantes Saavedra, abreviado por un entusiasta del autor para el uso de los niños y de toda clase de personas ${ }^{2}$. A partir de entonces, la segunda mitad del siglo XIX, la lectura de la novela fue más regular en el mundo académico, artístico y político, con va-

\footnotetext{
1. Para un panorama a los procesos de democratización de la educación pública en Chile, ver REVEDUC. Revista de educación, núm. 381, monográfico al tema.

2. José Toribio Medina advierte que hasta 1850 no existía ningún ejemplar de la novela de Cervantes en los escaparates de las principales bibliotecas de Santiago. La primera edición chilena, de José Santos Tornero, se basó en la edición madrileña a cargo de Fernando de Castro, impresa un par de años antes en 1856, bajo el título El Quijote para todos, abreviado por un entusiasta de su autor Miguel de Cervantes Saavedra. La principal diferencia entre ambas ediciones son sus ilustraciones y los capítulos XI y XII de la Segunda Parte del Quijote que añade la edición de Valparaíso. Para un análisis de sus variantes, ver Villalobos, 2017. Un segundo hito importante en la difusión del cervantismo en Chile fue la primera conmemoración, en 1878, del CCLXII aniversario de la muerte de Cervantes, promovida por el profesor del Instituto Pedagógico Enrique Nercaseaux y Morán; ver Medina, 1958 y Villalobos, 2017.
} 
rias recreaciones locales ${ }^{3}$. Sin embargo, su difusión en los centros educativos aún es débil. En los actuales programas de estudio del currículum chileno se sugieren dieciséis capítulos del Quijote para ahondar diversos objetivos transversales de aprendizaje de la asignatura de Lengua y Literatura, de quinto básico a segundo medio. A saber:

\begin{tabular}{|l|l|l|}
\hline Nivel & Unidad temática & Texto \\
\hline $\begin{array}{l}\text { Quinto } \\
\text { básico }\end{array}$ & Unidad 2 & $\begin{array}{l}\text { Capítulo VIII: Episodio de los molinos } \\
\text { de viento [Primera parte 1605]. }\end{array}$ \\
\hline $\begin{array}{l}\text { Sexto } \\
\text { básico }\end{array}$ & Unidad 3 & $\begin{array}{l}\text { Capítulo XXV: Donde se apunta la aventura } \\
\text { del rebuzno [Segunda parte 1615]. }\end{array}$ \\
\hline $\begin{array}{l}\text { Séptimo } \\
\text { básico }\end{array}$ & $\begin{array}{l}\text { Héroe en } \\
\text { distintas épocas }\end{array}$ & $\begin{array}{l}\text { Capítulo XXII: Aventura de los galeotes } \\
\text { [Primera parte 1605]. }\end{array}$ \\
\hline $\begin{array}{l}\text { Séptimo } \\
\text { básico }\end{array}$ & $\begin{array}{l}\text { La identidad: } \\
\text { ¿Quién soy y cómo } \\
\text { me ven los demás? }\end{array}$ & $\begin{array}{l}\text { Capítulos XXX y XXXI: La embajada } \\
\text { de Sancho ante Dulcinea [Primera parte 1605]. }\end{array}$ \\
\hline $\begin{array}{l}\text { Séptimo } \\
\text { año }\end{array}$ & $\begin{array}{l}\text { La solidaridad } \\
\text { la amistad }\end{array}$ & $\begin{array}{l}\text { Capítulo XVII: El bálsamo de Fierabrás } \\
\text { [Primera parte 1605]. }\end{array}$ \\
\hline $\begin{array}{l}\text { Octavo } \\
\text { año }\end{array}$ & Experiencias del amor & $\begin{array}{l}\text { Capítulos XII y XIII: Episodio de la pastora } \\
\text { Marcela [Primera parte 1605]. }\end{array}$ \\
\hline $\begin{array}{l}\text { Primero } \\
\text { medio }\end{array}$ & $\begin{array}{l}\text { La astucia } \\
\text { yla sabiduría }\end{array}$ & $\begin{array}{l}\text { Capítulos XLV y XLVII: Juicios de Sancho } \\
\text { Panza [Segunda parte 1615]. }\end{array}$ \\
\hline $\begin{array}{l}\text { Segundo } \\
\text { medio }\end{array}$ & El trabajo & $\begin{array}{l}\text { Capítulo XXXVIII: El discurso de las armas } \\
\text { y las letras [Primera parte 1605]. }\end{array}$ \\
\hline $\begin{array}{l}\text { Segundo } \\
\text { medio } \\
\text { medio }\end{array}$ & $\begin{array}{l}\text { Capítulo LIV: historia de Ricote el moro } \\
\text { [Segunda parte 1615]. }\end{array}$ \\
\hline $\begin{array}{l}\text { Segundo } \\
\text { [Primera parte 1605]. }\end{array}$ \\
\hline
\end{tabular}

Si bien los capítulos de la novela se proponen de manera oficial, son finalmente los/as docentes quienes seleccionan las lecturas para el aula, y es ahí donde estos se descartan, pues se carece de un material didáctico que facilite su estudio. El catálogo de las Bibliotecas Escolares CRA, del Ministerio de Educación de Chile, arroja trece entradas para el título Quijote, tres de ellas son recreaciones hispanoamericanas de literatura infantil (de las editoriales Santillana-Chile, Sirpus-España y El gato de hojalata-Argentina), una edición abreviada de la editorial británica

3. El Centro Virtual Miguel de Cervantes publicó una recopilación de artículos críticos sobre el Quijote en Chile, a cargo de Luis Correa-Díaz; ver https://cvc.cervantes.es/literatura/quijote_america/chile/default. htm. Para la recepción del Quijote en Chile, ver también el artículo de Correa-Díaz, 2008. 
Pearson-Alhambra, cuatro ediciones íntegras de las editoriales españolas: Cátedra, Biblioteca Edaf, RAE y Editorial Mare Nostrum, una biografía de Cervantes del coIombiano Nahum Montt, de Editorial Panamericana-Colombia (2006), y cuatro recreaciones chilenas: El Quijote de Matta, publicado por Germana Matta en Editorial Electa (2012), El príncipe de la locura. Hacia una psicología del «Quijote» de Sergio Peña y Lillo, de Editorial San Pablo (1993), El galgo de don Quijote de Víctor Carvajal, de la editorial Sol y Luna (2006), y una grabación sonora de la versión chilena del musical El hombre de la Mancha del compositor norteamericano Dale Wasserman $(2016)^{4}$. Es un anhelo del cervantismo chileno crear nuevas didácticas que difundan una lectura situada del Quijote. De alguna manera nuestro trabajo se identifica con el 'delirio pedagógico de Cervantes', según narra en la dedicatoria al conde de Lemos en la Segunda parte Don Quijote de la Mancha.

Es mucha la priesa que de infinitas partes me dan a que la envíe [el Quijote] ...y el que más ha mostrado desearle ha sido el grande Emperador de la China, pues en lengua chinesca habrá un mes que me escribió una carta con un propio, pidiéndome, o, por mejor decir, suplicándome se le enviase, porque quería fundar un colegio donde se leyese la lengua castellana, y quería que el libro que se leyese fuese el de la historia de don Quijote. Juntamente con esto me decía que fuese yo a ser el rector del tal colegio ${ }^{5}$.

\section{EL CASO DE DULCINEA ENCADENADA, FUNCIONALIZACIÓN PEDAGÓGICA DE UNA RECREACIÓN TEATRAL CERVANTINA}

Los contextos de la conmemoración del IV centenario de la publicación de la Segunda parte del Quijote el 2015, como de la muerte de Miguel de Cervantes, el año 2016, permitieron que el cervantismo adquiriese un nuevo brío de creación e investigación bajo diversos formatos narrativos, desde el cine, al teatro, la música y las artes plásticas ${ }^{6}$. En el caso de Chile, el teatro profesional llevó a escena tres montajes. Una reescritura de El licenciado Vidriera, que tuvo por título Lamendero y fue dirigida por Guillermo Ugalde; una versión en formato de coros ciudadanos (un elenco con más de 60 actores y actrices) del Cerco de Numancia, dirigida por Visnu y Gopal Ibarra, y El retablo de las maravillas, dirigida por Macarena Baeza? ${ }^{7}$. Este mismo año, 2016, surge en Santiago de Chile la compañía Teatro del Nuevo Mundo, dirigida por los hermanos Tania y Rodrigo Faúndez Carreño, la primera (directora y actriz) y el segundo (filólogo y dramaturgo). El interés de este grupo artístico es presentar temas de inspiración clasicista, como el teatro del Siglo de Oro, que abordan

4. Ver la entrada de la Biblioteca Escolar (CRA): http://www.bibliotecas-cra.cl/. En España se ha creado una copiosa bibliografía didáctica a partir del Quijote con poco impacto en Chile. Para un balance de ediciones escolares españolas, ver Martín, 2007. También Alfaro Torres y Sánchez García, 2006.

5. Cervantes, Don Quijote de la Mancha, II, dedicatoria, p. 5.

6. Para un panorama de las recreaciones cervantinas en el arte y la literatura, ver Mata Induráin, 2016.

7. Posteriormente a dicha celebración se han estrenado en Chile otras recreaciones cervantinas como Dulcinea encadenada (2018) de Teatro del Nuevo Mundo, Súper don Quijote (2018), de Escénica y ArtChili (de Cristian Zurita y Paloma Gordián), y Ser o no Cervantes (2019), teatro infantil, de Kalén Compañía Teatral. 
desde un punto de vista barroco latinoamericano y una estética postdramática. El indigenismo, la guerra, el género y la prisión política están presentes en sus trabajos: Auto sacramental La Araucana (2016) y Dulcinea encadenada (2018)8.

Esta última es una recreación teatral cervantina, apócrifa y postcolonial. Su protagonista, Dulcinea, y los personajes alegóricos Eco y Wamani transitan en un recorrido de imágenes y situaciones poéticas que denuncian el 'ser mujer y latinoamericana', utilizando como pretexto algunos pasajes canónicos del Quijote de la Mancha9. Se estrenó en Santiago el 24 de abril del año 2018 en el Centro cultural de España en Santiago de Chile (CCES), y tuvo una mediación escolar en la Región de Ñuble, el año 2019, bajo el amparo de la Universidad del Bío-Bío en el marco del proyecto de extensión relevante «Teatro, Universidad y Educación Pública», en alianza con el proyecto Fondecyt de iniciación 11180910. La mediación permitió crear dos instrumentos didácticos, un Taller de espectadores teatrales y un Cuadernillo didáctico multimodal en función de las asignaturas de Lengua y Literatura y Orientación. Participaron de las actividades siete escuelas públicas de la Región de Ñuble ${ }^{10}$.

\subsection{Taller de espectadores teatrales}

Taller de espectadores teatrales es una mediación pedagógica de investigaciónacción ${ }^{11}$. Se ejecutó en 90 minutos, días antes de la función teatral, para ahondar en la vida y obra de Miguel de Cervantes como algunos discursos clave de la novela el Ingenioso hidalgo don Quijote de la Mancha, subyacentes a la dramaturgia de Dulcinea encadenada. Dos talleristas, estudiantes de la carrera de Pedagogía en Castellano y Comunicación de la Universidad del Bío-Bío, abordan: 1) Una biografía de Miguel de Cervantes, 2) Argumento del Quijote de la Mancha, 3) El discurso de las armas y las letras, 4) La aventura de los galeotes, 5) El discurso de la Edad Dorada y 6) El discurso de la pastora Marcela.

8. Para un registro de los trabajos de la compañía Teatro del Nuevo Mundo, ver Auto sacramental La Araucana: https://youtu.be/bn-KDBTh4Gg y Dulcinea encadenada: https://youtu.be/ohsjw607hWk. Ver también T. Faúndez Carreño, 2020.

9. El equipo creativo lo integran Bárbara Santander, actriz, Carolina Pinto, actriz, y Renato Vázquez, actor. Diseño integral de Francisca Bravo, Diseño gráfico de Joselyn Pineda. Dirección de Tania Faúndez y dramaturgia de Rodrigo Faúndez.

10. El proyecto de extensión relevante «Teatro, Universidad y Educación Pública» de la Universidad del Bío-Bío permitió que 500 escolares de la Región de Ñuble asistieran a las tres funciones gratuitas de Dulcinea encadenada en la ciudad de Chillán. En cuanto a la condición socioeconómica de los/ as estudiantes, el $80 \%$ son alumnos/as prioritarios y preferentes del sistema de protección social, ver: http://datos.mineduc.cl/datasets/191000/alumnos-prioritarios-preferentes-yo-beneficiariosano-2019/. Un 70\% de los/as asistentes participaron del Taller de espectadores teatrales y un 30\% de las muestras del Cuadernillo didáctico.

11. La mediación pedagógica, de investigación-acción, se entiende como un proceso en construcción, evaluación y creación de nuevas preguntas a partir de la interacción con la comunidad. Antonio Latorre define investigación-acción como una práxis donde: «El profesorado como investigador formula nuevas cuestiones y problematiza sus prácticas educativas. Los datos se recogen en el transcurrir de la práctica en el aula, se analizan e interpretan y vuelven a generar nuevas preguntas e hipótesis para ser sometidas a indagación» (2003, p. 10) 
La intervención fue pensada para estudiantes de séptimo a segundo medio, en un universo etario de 12 a 15 años. Se organizó en tres etapas:

1) Inicio de 20 minutos, en los que se hace referencia a los puntos 1 y 2 , mediante un power point que interroga a los/as estudiantes desde una didáctica selectiva y dirigida, con la finalidad de nivelar conocimientos previos y motivarles.

2) El desarrollo, de 60 minutos, aborda las temáticas 3 a 6 , utilizando diferentes ejercicios escénicos, inspirados en una pedagogía teatral ${ }^{12}$. Por ejemplo, la actividad número 4 que presenta La aventura de los galeotes la denominamos «De la narración al diálogo»; en ella, los/as estudiantes en conjunto con los/as docentes interpretan el pasaje de la novela de Cervantes como una lectura dramatizada. Algunos/as son don Quijote y otros/as los presos y guardias del capítulo. Con ello, buscamos potenciar la capacidad declamatoria, interpretativa y vocabulario de los/ as participantes. En medio de estos diálogos se van haciendo pausas donde se explican aspectos históricos, lingüísticos y poéticos de la novela, aproximándolos/ as al marco cultural del Siglo de Oro.

Otro ejercicio escénico es la representación de la historia de la pastora Marcela y Grisóstomo, interpretada por los talleristas. Sus diálogos permiten exponer el tema del acoso y el amor forzado desde un punto de vista contemporáneo, el que luego es discutido en colectivo. El pasaje de la novela permite analizar la antigüedad del acoso callejero y la violencia contra la mujer en la literatura. Se traza un vínculo entre las problemáticas del siglo XVI y las del siglo XXI.

Un tercer ejercicio está inspirado en el Kamishibai o 'drama en papel' de origen japonés, que permite dar un soporte visual al Discurso de la Edad dorada del Quijote. A través de una serie de imágenes se busca captar la atención del espectador, promover su interés por la lectura de la novela y su recreación gráfica. Los/as alumnos/as van descifrando los dibujos y reconstruyendo la historia. Todos estos ejercicios son lúdicos y participativos, predisponiendo a la audiencia de manera positiva para el espectáculo teatral.

3) El taller finaliza con un momento de cierre de 10 minutos, en los que se comparten opiniones, se expreasn expectativas de la visita al teatro y se evaluán las actividades llevadas a cabo.

Luego de la ejecución del Taller escuela de espectadores teatrales, en el horario de la jornada escolar, los/as estudiantes de los centros escolares vinculados al proyecto «Teatro, Universidad y Educación Pública» visitaron la sala Schäfer del Centro de Extensión de la Universidad del Bío-Bío en Chillán, el 25 de abril del año 2019, para ver una de las tres funciones gratuitas de Dulcinea encadenada y protagonizar un conversatorio con el equipo creativo: intérpretes, directora, diseñadora integral y dramaturgo. Ambas actividades se evaluaron a través de una encuesta de satisfacción. 
La encuesta de satisfacción, creada y validada por un equipo de académicos especialistas, se compone de seis preguntas que abordan tres áreas: el cervantismo, la experiencia didáctica del Taller de espectadores teatrales, y la vivencia teatral. Estas interrogantes son de tipo de abierta, permitiendo a los/as estudiantes explayarse sobre cada una de las tres áreas ${ }^{13}$.

Los resultados revelan que el $98 \%$ de la/os estudiantes valoraron positivamente tanto la visita al teatro, la función de la obra y el Taller de espectadores teatrales, pues ninguno de ellos tenía conocimientos previos del Quijote, ni de la vida y obra de Miguel de Cervantes. Respecto del taller, la mayoría de la/os estudiantes, un $85 \%$, piensa que su extensión es pertinente, pues les permitió disfrutar de las actividades y reflexionar en torno a los contenidos abordados. Solo un $15 \%$ lo percibió como una actividad muy extensa ${ }^{14}$.

En relación con la visita al teatro la destacaron como una experiencia sin parangón pues pocas veces tienen la posibilidad de salir de la escuela. Otros/as declararon no haber asistido antes a una representación teatral.

Respecto del espectáculo teatral, los/as estudiantes apreciaron el diseño escenográfico, la música, la iluminación y la interpretación del elenco; la capacidad que tienen los actores de cambiar sus voces y fisonomías para interpretar varios personajes. Ninguno había participado de un conversatorio con una compañía de teatro, por ende, sienten que conocieron 'desde dentro' el mundo de las tablas, que valoraron como un espacio ameno y ahora cercano.

\subsection{Cuadernillo didáctico}

Con el objetivo de funcionalizar pedagógicamente la obra de teatro Dulcinea encadenada a merced de las bases curriculares y programas de estudio de la educación formal chilena, se creó un Cuadernillo didáctico multimodal adaptado a los Objetivos de Aprendizaje (OA) y Objetivos de Aprendizaje Transversales (OAT) de séptimo a segundo medio de Lengua y Literatura, como a los de la disciplina de Orientación ${ }^{15}$.

El Cuadernillo tiene dos formatos. Uno pensado para la/os docentes, que consta de 31 actividades, 2 secuencias didácticas, 3 situaciones evaluativas; y un segundo formato para los/as estudiantes, con 31 actividades que promueven la lectura, expresión escrita y oral. El Cuadernillo está organizado en 13 actividades de Lengua y Literatura, con énfasis en el estudio del género dramático, el género lírico, la métrica y gramática. 5 actividades del área de Comunicación (debate, argumentación, expresión oral y escrita). 9 de Orientación (trabajo colaborativo, afectividad, identidad,

13. Para un análisis porcentual gráfico a la encuesta de satisfacción, ver Anexos de la tesis de Medina Burgos, 2019.

14. Ver Medina Burgos, 2019, p. 255.

15. Para los objetivos de aprendizaje de los planes y programas, ver https://curriculumnacional.mineduc.cl/. 
fortalezas y proyectos personales), y 4 actividades mixtas, es decir, que abordan ambas asignaturas $^{16}$.

De todo el Cuadernillo fue posible aplicar, de modo exploratrio, cuatro actividades en la escuela rural San Jorge de Ñiquén, en un universo de 30 estudiantes de séptimo básico. Comentamos dos experiencias del trabajo en aula bajo una metodología de observación directa, una correpondiente a la asignatura de Lengua y Literatura y la otra de Orientación.

\section{Cuadernillo didáctico: Características del género dramático (actividad 14)}

A partir de la lectura de la dramaturgia de Dulcinea encadenada los/as alumnos diferencian los elementos del lenguaje teatral, actos, cuadros, lenguaje acotacional y escénico. Reconocen los parlamentos de la obra y las indicaciones del dramaturgo. En base a la observación de fotografías, se propicia una reflexión en torno al cuerpo, movimientos y actitud de las actrices que vinculan con la representación teatral, como su atmósfera indigenista y carácter ritual.

Los resultados más relevantes de esta experiencia fueron los comentarios de los/ as estudiantes quienes reiteraron las palabras castigo, injusticia, dolor, admiración y rito. Los/as estudiantes rememoraron la experiencia teatral a partir de esta actividad.

\section{Cuadernillo didáctico: Crecimiento personal (actividad 24)}

Después de la lectura de un fragmento de la dramaturgia los/as estudiantes completaron un escudo de armas en el que plasmaron cuatro aspectos de su personalidad 1) Lo mejor que cada uno/a ha conseguido, 2) La cualidad personal más importante, 3) Su afición o hobby y 4) Lo que se desea para el futuro.

Dentro de las respuestas que los estudiantes consideraron a la hora de completar su escudo de armas, el plano académico es uno de los aspectos más sobresalientes pues la mayoría, 85\%, hace referencia a la experiencia de la educación formal y sus expectativas. Muchos anhelan cursar una carrera universitaria, ser responsables y tener un buen desempeño en el SIMCE (Sistema de Medición de Calidad en Educación). En los/as estudiantes predomina una sensación comprometida y agradable con el saber. En general, manifiestan una disposición a instruirse y al conocimiento que valoran como una virtud. Varios/as de ellos/as son músicos/as y otros/as tienen una afinidad con los deportes, el ajedrez, el canto y la danza. En sus escudos hacen referencias a sus propios cambios socioemocionales, como dejar de ser tímidos/as, tener más confianza en sí mismos/as, sobreponerse ante las críticas y ser felices. El desarrollo afectivo lo reconocen como un proceso de

16. Los cuadernillos son de uso público; fueron creados por Francisca Medina Burgos en el marco del Seminario de investigación para optar al título de Profesor de Castellano y Comunicación por la Universidad del Bío-Bío, el año 2019. Su trabajo formó parte del proyecto Fondecyt de iniciación 11180910. Para acceder al Cuadernillo del profesor, ver https://drive.google.com/file/d/1F-wjPC5dncumJYfTKwhnNN9YGJPwhDZT/view? usp=sharing . 
crecimiento y trabajo personal. Valoran los vínculos colectivos como la familia, el curso y las relaciones afectivas entre pares.

\section{CONCLUSIONES}

Las diversas actividades de mediación pedagógica de la obra teatral Dulcinea encadenada promueven tanto el cervantismo como el conocimiento disciplinar y transversal del currículum escolar en Chile a partir de ejercicios en los que el cuerpo, los sentimientos y su expresión, son objetos de una reflexión académica que invita a una comprensión integral de nuestro entorno y de nosotros/as mismos/as.

El teatro es una experiencia cognitiva y sensorial que estimula la creatividad, el trabajo colaborativo, la cultura de paz y evita situaciones de riesgo escolar. En este sentido, las actividades del Cuadernillo recogen los cuatro pilares de la educación formal basada en competencias, propuestas por el Informe a la Unesco de la comisión internacional sobre la educación para el siglo XXI, presidido por Jacques Delors, que estimulan: a) aprender a conocer; b) aprender a hacer; c) aprender a vivir juntos; d) aprender a ser ${ }^{17}$.

La experiencia pedagógica de la obra teatral Dulcinea encadenada es una pequeña contribución al bienestar y democractización de la escuela regional en Chile, que pocos vínculos tiene con el mundo profesional de las artes escénicas. Estamos conscientes de los desafíos que enfrenta la educación pública en su relación con el teatro, la danza y el circo, marginadas del currículum obligatorio y recluidas a la condición de 'talleres extraprogramáticos'. Es necesario superar esta mirada estetizante y superficial de las artes escénicas que las entienden como 'un fin en sí mismo', por una que las integre a la realidad escolar como una herramienta más en los anhelos de una educación transformadora.

Agradecemos a todos los agentes que participaron en el proyecto de creación teatral y mediación pedagógica de Dulcinea encadenada, a la Dirección de Extensión de la Universidad del Bío-Bío, a la Vicerrectoria de Investigación y Postgrado (VRIP) de la Universidad del Bío-Bío en Chillán, al Centro Cultural de España en Santiago en Chile (CCES), al proyecto Fondecyt de iniciación 11180910, a los integrantes de la compañía Teatro del Nuevo Mundo y las escuelas públicas de la Región de Ñuble: Liceo Martín Ruiz de Gamboa, Liceo República de Italia, Liceo Juan Arturo Pacheco Altamirano, Escuela La Castilla, Escuela Amanda Chávez, Escuela San Jorge de Ñiquén y la Escuela Quinchamalí, sin las que este proyecto hubiese quedado solo en el recinto teatral.

17. Ver Delors, 1996. También Bisquerra Alzina, 2003 y Stingo, 2016 


\section{Fotografías}

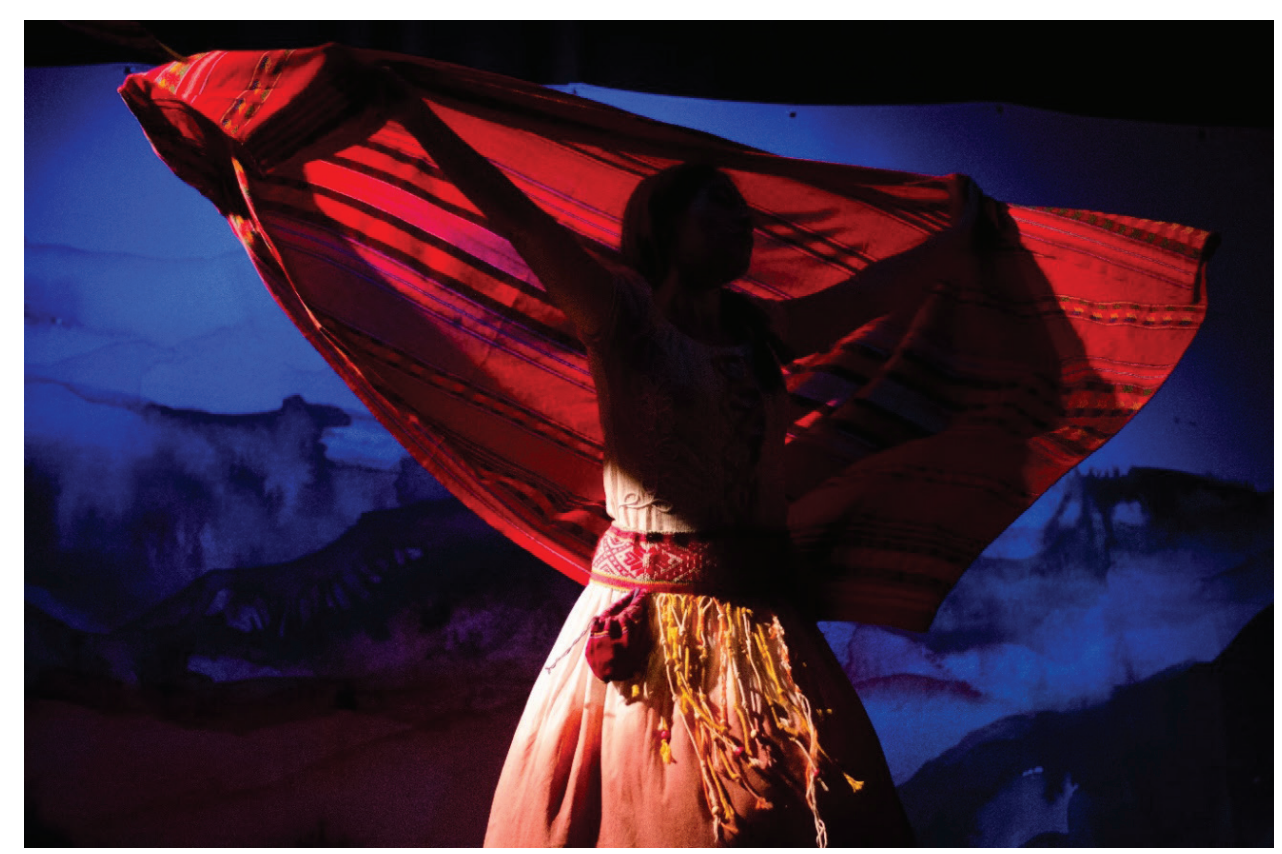

Dulcinea (Bárbara Santander). Fotografía: Lorenzo Mella

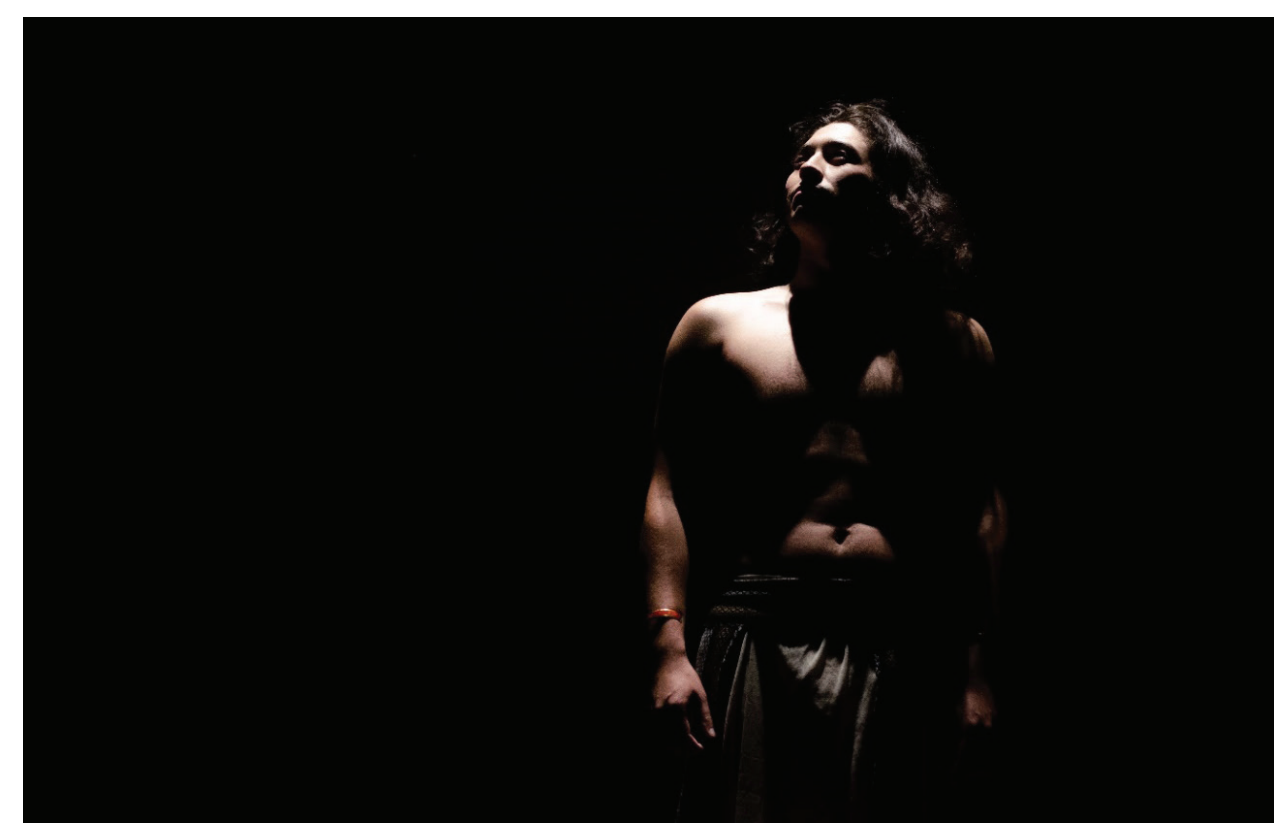

Wamani (Renato Vásquez)

HIPOGRIFO, 9.1, 2021 (pp. 1111-1122) 


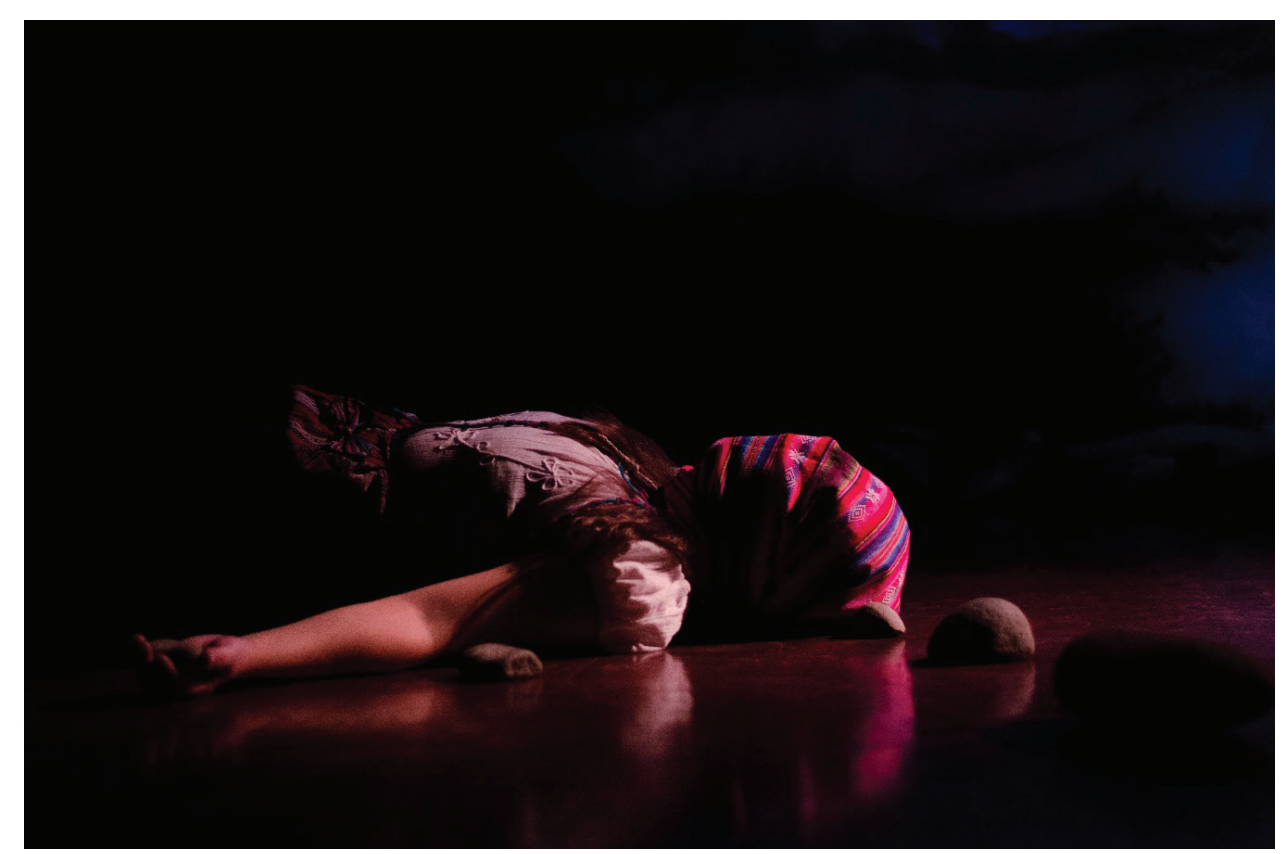

Eco (Carolina Pinto). Fotografía Lorenzo Mella

\section{BiBLIOgRAFÍA}

Alfaro Torres, Paloma, y Sánchez García, Sandra, «La lectura obligatoria del Quijote en las escuelas: análisis de ediciones escolares», en Don Quijote en el aula. La aventura pedagógica, coord. Ángel Cano Vega y Juan José Pastor, Ciudad Real, Universidad de Castilla-La Mancha, 2006, pp. 17-26.

Bisquerra Alzina, Rafael, «Educación emocional y competencias básicas para la vida», Revista de investigación en educativa, 21.1, 2003, pp. 7-43.

Cervantes, Miguel de, El ingenioso hidalgo don Quijote de la Mancha, Barcelona, Editorial Sol, 2002.

Correa-Díaz, Luis, «América y Cervantes / El Quijote: el caso de Chile», Revista Chilena de Literatura, 72, 2008, pp. 127-147.

Correa-Díaz, Luis, El «Quijote» en Chile, recopilación de Luis Correa-Díaz para el Centro Virtual Miguel de Cervantes: https://cvc.cervantes.es/literatura/quijote_america/chile/default.htm.

Delors, Jacques, Informe a la Unesco de la comisión internacional sobre la educación para el siglo XXI, presidido por Jaques Delors. La educación es un tesoro, Madrid, Santillana / Unesco, 1996. 
Faúndez Carreño, Tania, «Dulcinea encadenada: una recreación teatral cervantina latinoamericana», Hipogrifo. Revista de literatura y cultura del Siglo de Oro, 8.2, 2020, pp. 915-924.

García-Huidobro, Verónica, Manual de pedagogía teatral, Santiago de Chile, Editorial Los Andes, 1996.

Latorre, Antonio, La investigación-acción: conocer y cambiar la práctica educativa, Barcelona, Editorial Graó, 2005.

Martín, Nieves, «El uso del Quijote en el aula. Revisión histórica de ediciones escolares y paratextos didácticos», Revista Ocnos, 3, 2007, pp. 77-90.

Mata Induráin, Carlos (ed.), Recreaciones quijotescas y cervantinas en las artes. Cervantes y su obra, Pamplona, Eunsa, 2016.

Medina, José Toribio, «Cervantes en las letras chilenas», en Estudios cervantinos, Santiago de Chile, Fondo Historiográfico y Bibliográfico José Toribio Medina, 1958, pp. 565-598.

Medina Burgos, Francisca, Funcionalización pedagógica de la obra «Dulcinea encadenada», para audiencias de séptimo a segundo medio en Lengua y Literatura, y Orientación. Su implementación pedagógica en establecimientos escolares de la Región de Ñuble, Seminario para optar al título de Profesora de Educación Media en Castellano y Comunicación, Chillán, Universidad del Bío-Bío, 2019.

Mistral, Gabriela, Magisterio y niño, ed. Roque Esteba Scarpa, Santiago de Chile, Editorial Andrés Bello, 1979.

Ponce, Héctor, y Olivares, Paulo, Teatro y Educación. Diálogos por una pedagogía crítica de la escena, Santiago de Chile, Editorial Jinete Azul, 2016.

REVEDUC. Revista de Educación, 381, 2017.

Stingo, Paulo, «Competencias teatrales al servicio de una educación integral», en Teatro y Educación. Diálogos por una pedagogía crítica de la escena, ed. Héctor Ponce y Paulo Olivares, Santiago de Chile, Editorial Jinete Azul, 2016, pp. 72-88.

Vázquez, Carlos Manuel, «Pedagogía teatral. Una propuesta teórico-metodológica crítica», Calle 14 Revista de investigación en el campo del Arte, 3, 2011, pp. 60-73.

Villalobos Lara, Raquel, El «Quijote» en Chile. Primera edición y estudios bibliográficos desde 1863 a 1947, Santiago de Chile, Ril Editores, 2017. 